\title{
BOCIO GIGANTE CÉRVICO-TORÁCICO*
}

\author{
Drs. Jorge Lavanderos F. ${ }^{1}$, Guillermo Cacciuttolo P. ${ }^{2}$, Juan Emilio Cheyre F. ${ }^{3}$
}

1 Instituto Nacional del Tórax, Universidad Austral de Chile.

2 Instituto Nacional del Tórax, Servicio Médico-Quirúrgico Respiratorio.

3 Instituto Nacional del Tórax, Universidad de Los Andes.

Santiago, Chile.

\section{Cervical-thoracic giant goiter}

Paciente de 60 años consulta por la aparición de vasos venosos en la cara anterior del tórax, asociado a disnea de esfuerzos (Figura 1). Estudio con Radiografía de tórax evidencia ensanchamiento mediastínico y desviación de la vía aérea. Se complementa estudio con Tomografía Computada en la cual se aprecia una masa tumoral de $8,2 \mathrm{~cm}$ en el mediastino anterior, que se contacta con el lóbulo izquierdo de tiroides, el que se encuentra aumentado de tamaño y de estructura heterogénea. Esta masa produce compresión y desplazamiento de la tráquea hacia derecha (Figura 2). Paciente funcionalmente eutiroídea. Se realizó una tiroidectomía total mediante cervicotomía más esternotomía; cirugía en la cual se aprecia que la irrigación es dependiente de los vasos cervicales, con identificación y preservación de las glándulas paratiroides y de los nervios laríngeos recurrentes (Figura 3). Biopsia informa una glándula tiroides de $289 \mathrm{~g}$, de $13 \times 8,9 \times 6,5 \mathrm{~cm}$ de aspecto macroscópico multinodular, que al examen microscópico presenta hiperplasia nodular y una tiroiditis linfocitaria (Figura 4).

El primero en describir un bocio endotorácico fue el suizo Albrecht von Haller en 1749 y la primera cirugía por esta patología se adjudica a Klein en $1820^{1}$. Se han definido de distintas maneras, siendo una de las más utilizadas la de Katlic que lo define como aquel bocio que presenta más del $50 \%$ de su volumen dentro del tórax. Su crecimiento cervical se extiende caudalmente favorecido por la gravedad, la presión negativa intratorácica y el espacio ofrecido por el mediastino. El arco aórtico y los vasos subclavios ofrecen un obstáculo mayor a izquierda, por lo tanto, su crecimiento es más frecuente hacia derecha ${ }^{2-4}$.

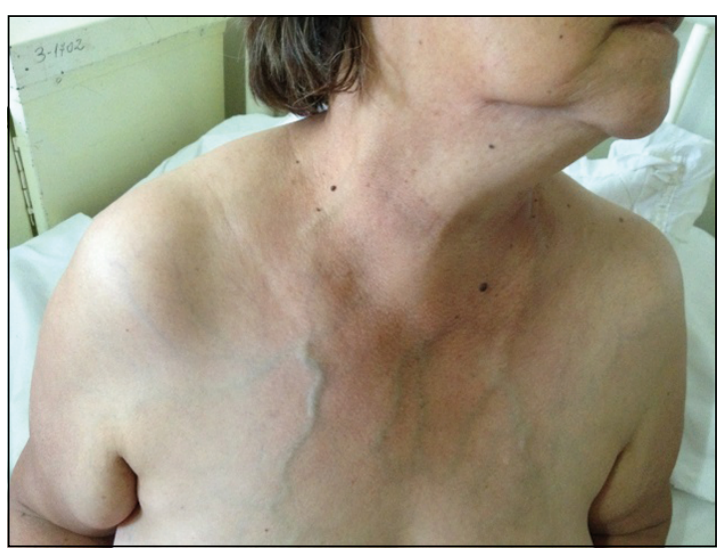

Figura 1. Circulación colateral secundaria a síndrome de vena cava superior.

*Recibido el 29 de septiembre de 2013 y aceptado para publicación el 2 de noviembre de 2013.

Los autores no refieren conflictos de interés.

Correspondencia: Dr. Jorge Lavanderos F. jlavanderosfernandez@yahoo.com 

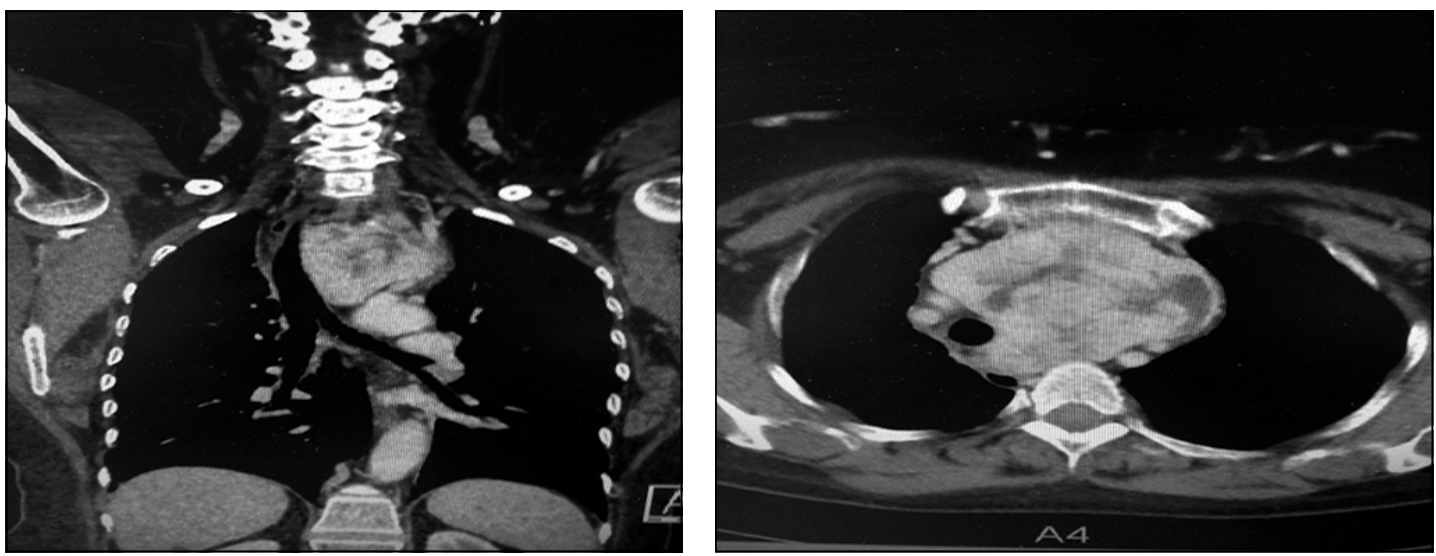

Figura 2. Desplazamiento de la tráquea hacia derecha. Izquierda: corte coronal. Derecha: corte axial.

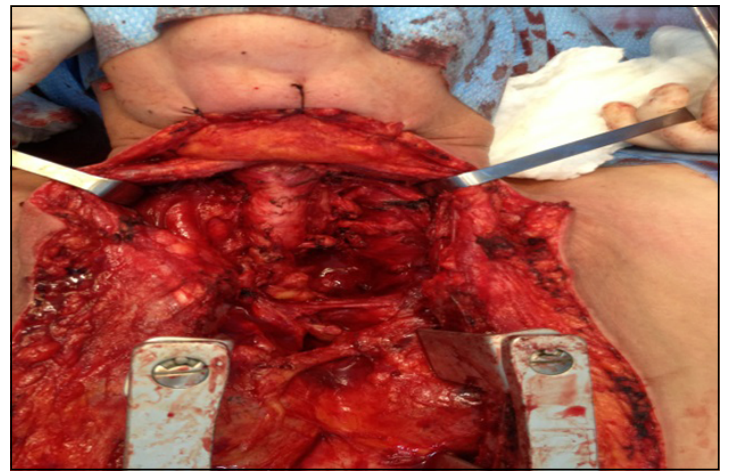

Figura 3. Lecho tumoral post extracción de pieza operatoria.

Aparece con mayor frecuencia en el mediastino anterior y funcionalmente la mayoría de los pacientes son eutiroídeos. En el estudio con imágenes la herramienta de elección es la Tomografía Computada puesto que nos informa con exactitud sobre las dimensiones de la lesión, su extensión y la relación con estructuras vecinas. Histopatológicamente corresponden mayoritariamente a lesiones benignas ${ }^{1,2}$. En pacientes asintomáticos la indicación de tratamiento se fundamenta ante la sospecha de malignidad, a que las hemorragias intratumorales pueden convertirse en una urgencia quirúrgica y que la compresión de la vía aérea puede producir traqueomalacia.

El Gold Standard de manejo corresponde a la tiroidectomía total. La remoción parcial del tiroides disminuye el riesgo quirúrgico, pero aumenta las tasas de recidiva. La mayoría de las lesiones se pueden resecar mediante cervicotomía, en lesiones cérvico-torácicas de gran tamaño se recomiendan abordajes mixtos y las lesiones puramente torácicas

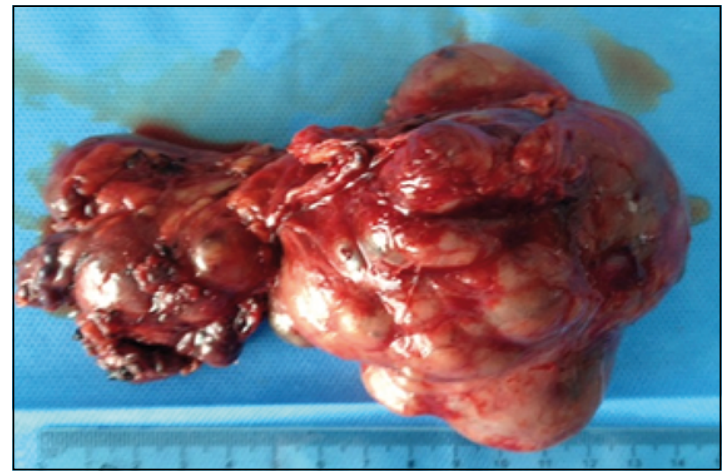

Figura 4. Pieza quirúrgica.

se pueden abordar por esternotomía o toracotomía; esta última cuando el bocio se encuentra en el mediastino posterior.

\section{Referencias}

1. González O, Simkin D, Pardo H, Seva R, Delgado $\mathrm{D}$, Dávila S. Bocio cervicotorácico ¿De qué depende el abordaje torácico? Revista Argentina de Cirugía 2011;100:23-8.

2. González L, Cifuentes C, Jadue A, Prats R, Santolaya R, Rodríguez $\mathrm{P}$. Caracterización y resultados inmediatos en pacientes con tratamiento quirúrgico de bocio intratorácico. Rev Chil Cir. 2012;64:426-33.

3. De Aquiar-Quevedo K, Cerón-Navarro J, Jordá-Aragón C, Pastor-Martínez E, Sales-Badía J, García-Zarza A, et al. Intrathoracic goitre: a literature review. Cirugía Española 2010;88:142-5.

4. González R, Corona S, Salinas J, López M, Infante A. Resultado del tratamiento quirúrgico del bocio endotorácico. Revista Cubana de Cirugía 2007;46:1-8. 